\title{
Bone density in osteogenesis imperfecta may well be
} normal

\author{
Colin R. Paterson and Patricia A. Mole \\ Department of Biochemical Medicine, University of Dundee, Ninewells Hospital and Medical School, \\ Dundee DD1 9SY, UK
}

\begin{abstract}
Summary: Osteogenesis imperfecta (OI) is often regarded as a form of osteoporosis. However, the bone fragility is the result of defective collagen and earlier work has demonstrated that cortical thickness, in bones not previously fractured, is usually normal. We have now measured the bone mineral content of the distal forearm in 61 adult patients with well characterized OI.

Three patients with the Sillence type III disorder had bone mass values well below the reference interval. For the 47 type I patients and 11 type IV patients, the bone mass was significantly lower than normal $(P<0.001)$. However $70 \%$ of patients had values within the reference interval. One cannot therefore exclude the diagnosis of $\mathrm{OI}$ by finding normal values with densitometry.

Diagnostic difficulties do not occur in type III patients and our main objective was to recruit as many individuals as possible with OI types I and IV. In the type IV disease, the diagnosis can be particularly difficult without a positive family history. Since the evaluation of bone density by subjective examination of radiographs is a much less precise procedure, most patients with type I and IV OI would be expected to have 'normal' appearances with this assessment. Osteogenesis imperfecta cannot be excluded on the basis of apparently normal bone density or cortical thickness with routine radiographs.
\end{abstract}

\section{Introduction}

Osteogenesis imperfecta (OI) has often been regarded in the past as a form of osteoporosis. ${ }^{1,2}$ However, it is increasingly clear that almost all cases result from heritable disorders of collagen rather than from any defect of calcium metabolism. In recent years the extreme heterogeneity of OI has been recognized, a wide range of distinct molecular defects having been identified. ${ }^{3}$

In earlier work we showed that the bones of adults with OI frequently had normal radiological appearance, particularly in bones that had not sustained previous fractures. ${ }^{4}$ The thickness of the metacarpal cortex in 24 adults was within the normal range. ${ }^{5}$ On the other hand, diminished bone density in the spine, measured by quantitative computed tomography in 28 patients, has been found, particularly in the more severely affected patients. ${ }^{6}$ Histomorphometry of biopsy samples from the iliac crests showed reduced values for trabecular bone volumes in six out of eight adults with $\mathrm{OI}^{7}$ A reduced bone formation rate was inferred from a diminished calcification rate.

In order to resolve these apparently conflicting

Correspondence: C.R. Paterson, D.M., F.R.C.P.(Ed.). Accepted: 22 September 1993 findings, it seemed important to determine the bone mineral density in larger numbers of patients and to compare the results with those from a local reference control group. In this way it was hoped that the potential value of such measurements in the diagnosis of OI could be assessed.

\section{Patients and methods}

The patients were recruited by contacting all those known to the Brittle Bone Society aged over 20, resident in Scotland and within a one-day return journey of Dundee. Of the 71 eligible patients, four could not be classified with the Sillence scheme (Table I), nine did not reply and ten were unwilling to attend for various reasons, leaving 48 who were studied. An additional 13 patients from England were recruited while on holiday in Scotland, giving a study population of 61 .

Of the eight patients with type IV OI, there was a clear family history in three. The other five patients were thought to have OI resulting from new mutations; all had classical histories of fractures up to at least the age of 13 , and three of them had overt dentinogenesis imperfecta.

The control group consisted of 380 local volunteers drawn from hospital and local authority 
Table I Clinical classification of patients with osteogenesis imperfecta proposed by Sillence et al. ${ }^{8}$

\begin{tabular}{lll}
\hline $\begin{array}{l}\text { Sillence } \\
\text { type }\end{array}$ & \multicolumn{1}{c}{ Clinical features } & \multicolumn{1}{c}{ Inheritance } \\
\hline I & $\begin{array}{l}\text { Mild to moderate severity. } \\
\text { Little impairment of growth. } \\
\text { Blue sclerae at all ages. }\end{array}$ & $\begin{array}{l}\text { Autosomal dominant. } \\
\text { New mutations occur frequently. }\end{array}$ \\
II & $\begin{array}{l}\text { Very severe disease causing stillbirth } \\
\text { or early neonatal death. }\end{array}$ & $\begin{array}{l}\text { Not known in most cases. Most probably } \\
\text { result from new dominant mutation. } \\
\text { III }\end{array}$ \\
$\begin{array}{l}\text { Severe disease with antenatal fractures in } \\
\text { most cases. Progressive deformity common. }\end{array}$ & $\begin{array}{l}\text { Most probably result from new dominant } \\
\text { mutations. Autosomal recessive in some. }\end{array}$ \\
Severe impairment of growth. \\
Blue sclerae in some but not all cases. \\
Dentinogenesis imperfecta common. \\
IV*
\end{tabular}

*Subdivided into (A) no overt dental abnormality, and (B) dentinogenesis imperfecta present.

employees, church and voluntary group members, and over-60s exercise class attenders. All were free from treatment with corticosteroids, hormone replacement therapy, excessive alcohol intake, and any disease known to affect calcium metabolism or bone density. None had had previous fracture of the non-dominant distal forearm.

A Molsgaard single photon absorptiometer (Nuclear Data ND1100A) was used to measure the bone mineral content (BMC) of the non-dominant forearm. The value for the distal site was the mean of four scans in $2 \mathrm{~mm}$ increments distal to the $8 \mathrm{~mm}$ interosseous space between the radius and ulna. For the proximal site the value was the mean of six scans in $4 \mathrm{~mm}$ increments proximal to the $8 \mathrm{~mm}$ interosseous space. The coefficients of variation, taking measurements on one subject on ten occasions by two operators, were $1.3 \%$ for distal $\mathrm{BMC}$ and $1.2 \%$ for proximal BMC.

Results are in arbitrary units after correction for fat absorption (BMC) and divided by bone width to give a value for bone mineral density (BMD); they were expressed as $z$-scores, the number of standard deviations of the patient's value from the mean of the appropriate age-band of the control population (5-year bands for women and 10-year bands for men).

\section{Results}

All three patients with the type III disorder had bone mass values well below two standard deviations below the normal mean for age and sex. For type I, the mean values for BMC and BMD at both distal and proximal sites were significantly lower than normal $(P<0.001)$. For the eight patients with type IV, the distal BMC and BMD were also significantly lower $(P<0.001)$, but there was no significant difference at the proximal site $(P>0.2)$. There were no significant differences between mean bone mass for type I and type IV at either site. However about $70 \%$ of patients with OI types I and IV had BMC or BMD values within two standard deviations of the mean for age and sex of the reference population (Figure 1 and Table II).

\section{Discussion}

It is not surprising that the three patients with OI type III had bone density values well below the lower reference interval. However, diagnostic difficulties do not occur in such patients and our main objective was to recruit as many individuals as possible with types I and IV. In the type IV disease the diagnosis can be particularly difficult without a positive family history. ${ }^{4}$

We showed that, as a group, patients with OI type I had a diminished bone density relative to the control subjects. This difference may well reflect the inclusion, within this group, of some patients whose genetic defect is a 'null allele' leading to diminished collagen formation. ${ }^{9}$ Such patients could well have osteopenia as an integral part of the disease.

The fact that most patients both with OI type I and OI type IV had values for bone density within the reference interval is consistent with the fact that the most common biochemical disorder is defective collagen structure. ${ }^{3}$ The defective collagen may still permit normal mineral deposition; in such cases the 
Table II The percentage of osteogenesis imperfecta subjects within the reference interval of the control population for age and sex for bone mineral content (BMC) and bone mineral density (BMD) of the forearm at 'distal' and 'proximal' sites

\begin{tabular}{lcccc}
\hline Sillence type & $\begin{array}{c}\text { Distal } \\
B M C(\%)\end{array}$ & $\begin{array}{c}\text { Distal } \\
B M D(\%)\end{array}$ & $\begin{array}{c}\text { Proximal } \\
\text { BMC (\%) }\end{array}$ & $\begin{array}{c}\text { Proximal } \\
B M D(\%)\end{array}$ \\
\hline Type I & & & & 38 \\
Greater than -1 s.d. & 30 & 30 & 23 & 70 \\
Greater than -2 s.d. & 64 & 62 & 68 & 46 \\
Type IV & 27 & 36 & 36 & 82 \\
Greater than -1 s.d. & 64 & 82 & 64 & \\
Greater than -2 s.d. & 64 & & \\
\hline
\end{tabular}

s.d. = standard deviation

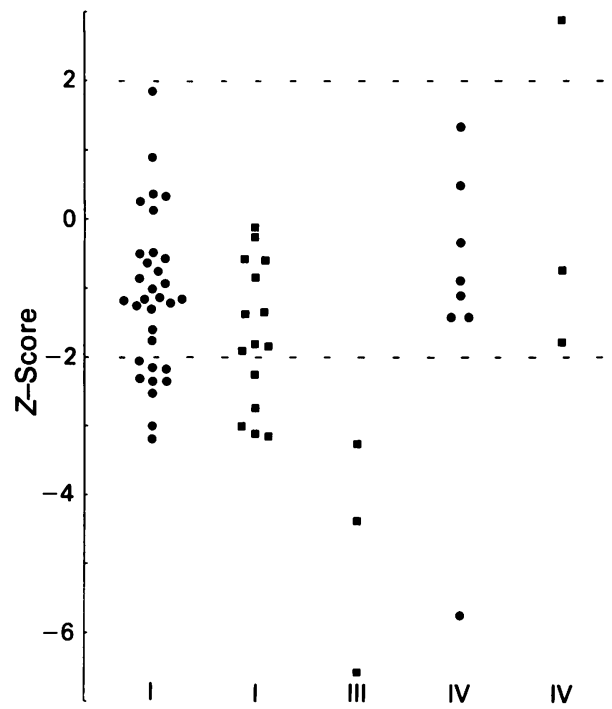

Figure 1 Bone mineral density (BMD) for the 'proximal' site of the forearm in osteogenesis imperfecta patients compared with the reference interval of a control population. BMD is expressed as $z$-score (standard deviation from the mean for an age- and sex-matched local population of normal subjects). $=$ female; $\mathbf{\square}=$ male.

bone fragility would initially be entirely due to the collagen abnormalities. It would later be compounded by osteopenia and deformity due to the fractures and the immobilization used in their treatment.

\section{References}

1. Sillence, D.O. Disorders of bone density, volume and mineralisation. In: Emery, A.E.H., Rimoin, D.L. (eds) Principles and Practice of Medical Genetics, Vol. 2. Churchill Livingstone, Edinburgh, 1983, pp. 736-751.
We recognize that only one method of densitometry was used and that ideally further work using dual energy $\mathrm{X}$-ray absorptiometry is needed. However, adults with OI often have scoliosis which would make the interpretation of any form of spinal densitometry difficult. Single photon aborptiometry (SPA) may be particularly appropriate in OI because it is a disorder that mainly causes long bone fractures. In addition a fair correlation has been found in osteoporosis between SPA on the forearm and measurements on the spine and on the whole body. ${ }^{10}$

While, as a group, patients with OI types I and IV have some diminution in bone density, the majority of patients had values within the reference ranges. One cannot therefore exclude the diagnosis of $\mathrm{OI}$ by finding normal values with densitometry. Since the evaluation of bone density by subjective examination of radiographs is a much less precise procedure, ${ }^{11-13}$ most patients with these disorders would be expected to have 'normal' appearances with this assessment. We wish to advise caution in attempting to 'exclude' osteogenesis imperfecta on the basis of apparently normal bone density or cortical thickness with routine radiographs.

\section{Acknowledgements}

We acknowledge the support of Mrs Marjorie Anderson, the Cunningham Trust and the Rehabilitation and Medical Research Trust. We thank Dr Margaret Walkinshaw for her help with the densitometry.

2. Horan, F. \& Beighton, P. Generalised decrease in bone density. In: Orthopaedic Problems in Inherited Skeletal Disorders. Springer-Verlag, Berlin, 1982, pp. 48-55. 
3. Byers, P.H., Wallis, G.A. \& Willing, M.C. Osteogenesis imperfecta: translation of mutation to phenotype. $\mathrm{J} \mathrm{Med}$ Genet 1991, 28: 433-442.

4. Paterson, C.R., McAllion, S.J. \& Shaw, J.W. Clinical and radiological features of osteogenesis imperfecta type IVA. Acta Paediatr Scand 1987, 76: 548-552.

5. Paterson, C.R. Metacarpal morphometry in adults with osteogenesis imperfecta. $\mathrm{Br}$ Med J 1978, 1: 213-214.

6. Kurtz, D., Morrish, K. \& Shapiro, J. Vertebral bone mineral content in osteogenesis imperfecta. Calcif Tissue Int 1985, 37: 14-18.

7. Ste-Marie, L.G., Charhon, S.A., Edouard, C., Chapuy, M.C. $\&$ Meunier, P.J. Iliac bone histomorphometry in adults and children with osteogenesis imperfecta. J Clin Pathol 1984, 37: $1081-1089$.

8. Sillence, D.O., Senn, A. \& Danks, D.M. Genetic heterogeneity in osteogenesis imperfecta. $J$ Med Genet 1979, 16: $101-116$.
9. Willing, M.C., Pruchno, C.J., Atkinson, M. \& Byers, P.H. Osteogenesis imperfecta type $I$ is commonly due to a COL1A1 null allele of type I collagen. Am J Hum Genet 1992, 51: 508-515.

10. Nilas, L., Podenphant, J., Riis, B.J., Gotfredsen, A. \& Christiansen, C. Usefulness of regional bone measurements in patients with osteoporotic fractures of the spine and distal forearm. J Nucl Med 1987, 28: 960-965.

11. Lachman, E. Osteoporosis: the potentialities and limitations of its roentgenologic diagnosis. Am J Roentgenol 1955, 74: 712-715.

12. Doyle, F.H., Gutteridge, D.H., Joplin, G.F. \& Fraser, R. An assessment of radiological criteria used in the study of spinal osteoporosis. Br J Radiol 1967, 40: 241-250.

13. Williamson, M.R., Boyd, C.M. \& Williamson, S.L. Osteoporosis: diagnosis by plain chest film versus dual photon absorptiometry. Skeletal Radiol 1990, 19: 27-30. 